\title{
Correlation between the Cognitive Impairment and the Performance of Activities of Daily Living among Elderly People Residing in Selected Old-Age Homes of West Bengal
}

\author{
Madhurima Kumar ${ }^{1}$, Shipra Modak ${ }^{2}$ \\ ${ }^{1}$ Priyamvada Birla Institute of Nursing, Kolkata 700156 \\ ${ }^{2}$ Government College of Nursing, I.D \& B.G Hospital Campus, Kolkata \\ Corresponding Author: Shipra Modak
}

\begin{abstract}
Age associated cognitive decline is an important human experience which differs in extent between individuals. Activities of daily living are linked to cognitive function. A descriptive study was conducted to identify correlation between the cognitive impairment $(\mathrm{CI})$ and the performance of activities of daily living (ADL) among elderly people residing in selected old-age homes of West Bengal. The study aimed to determine the relationship between the CI and the performance of ADL among elderly people. Non experimental survey research approach was adopted to collect data from 150 subjects by simple random sampling technique with the help of Demographic Proforma, GPCOG Screening Test and Barthel Index. The study findings revealed that $43.33 \%$ of the respondents had cognitive impairment whereas $56.66 \%$ were cognitively intact. ADL assessment depicted that $43.33 \%$ were moderately dependent, $33.33 \%$ were independent, $14.66 \%$ were slightly dependent, followed by $8.66 \%$ of the respondents who were severely dependent. A strong positive correlation was found between CI and ADL $(r=0.87)$ and also between CI and age $(r=0.97)$ of the participants. Statistically significant association was found between cognitive impairment and gender $\left(\chi^{2}=5.99\right.$, $<0.05)$, education $\left(\chi^{2}=8.81,<0.05\right)$, previous occupation $\left(\chi^{2}=12.80,<0.01\right)$, self financial support $\left(\chi^{2}\right.$ $=10.12,<0.01)$, family type $\left(\chi^{2}=15.77,<0.001\right)$, presence of chronic disease $\left(\chi^{2}=4.10,<0.05\right)$. Considering the findings some recommendations were offered for future research such as to conduct the study on large sample and different settings.
\end{abstract}

Key Words: Cognitive impairment, Activities of daily living, Elderly people, Correlation, Performance

\section{INTRODUCTION}

"Old age is not a disease - it is strength and survivorship, triumph over all kinds of vicissitudes and disappointments, trial and illnesses" $\sim$ Maggie Kuhn

"How old is old?" The concept of old has been changed drastically over the few years and is still changing. Our prehistoric ancestors probably had a life span of 40 years, with the average individual living around 18years [1]. Life expectancy in India has increased from 49.7 years in
1970-75 to 59 years in 1990s (male; 58.3 years and female; 59.7 years) and currently to 68.6 years in 2012-16. In current times, life expectancy of male is 67.4 years and for the female it is 70.2 years [2]. Old age depends not only on the chronological age of people, but also on their physical and mental abilities, socio economic resources, educational background, and previous life experiences because age alone cannot be a determining factor in defining old age [3]. Today, old age and gerontology have gained 
much more attention since the improved health conditions and increased life expectancy in the world have resulted in the boosting of the elderly population [4]. Besides this, because of the elongation of life span and the decline in birth rate, ageing crisis is spreading worldwide [5].

There are certain physiological as well psychological changes when it comes to aging. One of the domains that get affected while the process is going on is "the cognitive domain". It is said that the cognitive domain is the key that keeps an individual going; "The way to your body is through your spirit” [6].

Hence, as one gets older there are certain cognitive changes that occur with the process of aging (either normal or pathological). The most important changes in cognition are declines in performance on cognitive tasks that require one to quickly process or transform information to make decision, including measures of speed of processing, working memory, and executive cognitive function, which may accelerate the impairment of their everyday functional abilities [6].

Cognitive ability is a term referring to an individual's ability to process to thoughts that should not deplete on a large scale in healthy individuals. It is defined as the ability of an individual to perform the numerous mental activities most closely related to learning and problem solving [7].

For elderly to possess good conditions of life, they should be able to maintain their autonomy and their independence. The autonomy is considered as the ability to make decisions, that is, to be in control of life, and independence is seen as the ability and power to perform activities of daily living without depending on any other people [8].

Physical activity is one among the well-established lifestyle factors to take care of cognition. Various studies have indicated that, in healthy older people, higher physical activity is associated with higher cognitive performance and lower risk of cognitive impairment in later life. Existing literature shows that Functional Status (FS) decline is consistently related to cognitive impairment and is one of the most manifested features of dementia. Functional status can be measured by people's activities of daily living (ADL). Decline in functional status has also been proved to be a predictor of cognitive impairment in older people [5]. For the elderly, quality of life is associated with the ability to remain autonomous in the performance of daily living activities [9]. The 'Activities of daily living' or ADLs are the basic tasks of everyday life, such as eating, bathing, dressing, toileting and transferring [10].

Cognitive impairment (CI) is characterized by declines in memory, attention and cognitive function, which greatly affect the quality of life [5]. The World Health Organization (WHO) estimates that the number of people over the age of 60 will be around 2 billion in 2050, while the number of dementia patients is expected to rise rapidly along with the aging population [11]. According to the World Alzheimer Report, over 46 million people were living with dementia worldwide in 2015 , and this number is estimated to reach 131.5 million by 2050 [12].

Mild cognitive impairment (MCI) is often a precursor to Alzheimer disease (AD) and other forms of dementia, as $12 \%$ of individuals with MCI convert to AD over 1 year, and as many as $60 \%$ of people with MCI develop AD over a 5 years period. Individuals with MCI exhibit cognitive impairment but largely preserved functional abilities (Activities of Daily Living) comparable to that of cognitively normal older adults [13]. Cognitive decline is the defining characteristic of Alzheimer's disease as well as dementia. It significantly increases the risk of functional dependence and poor quality of life in the elderly [14].

Cognitive loss and conditions like dementia have a crucial impact on the capacity to conduct activities of daily living (ADL) in older people, leading to dependency, distress, and reduced quality of life [15]. Cognitive impairment affects 
people's ability to perform activities of daily life, initially in complex activities but later with the disease course, progressing to more basic activities such as dressing and toileting [16].

Cognitive impairments are among the most prevalent diseases in the elderly, and in more than half of the old people, mild cognitive impairment progresses to dementia within five years [4]. The prevalence of cognitive impairment grew significantly with age, with rates increasing by about $10 \%$ for every 10 years of age after age 65 . Of those aged 85 and older, $38 \%$ is having some degree of cognitive impairment [17].

Current data suggests that the prevalence of cognitive impairment in $65-$ year - olds is over $5 \%$, and their mortality is 3.3 - 6.0 times higher than that of the general population [11].

Also in a study, cross-sectional and longitudinal data have demonstrated that physically active people have lower risk of developing Alzheimer's disease and related cognitive disorders when compared with sedentary people [18]. Another study reveals that memory and executive functioning were related to IADL (Instrumental Activities of Daily Living) scores [19].

As the population in the world grows older, the number of people with cognitive impairment increases. More knowledge is needed about how cognitive impairment influences people's everyday life and their perceived quality of life [16]. This research aims to provide more evidence in this field.

\section{Need of the Study}

Age associated cognitive decline (either pathological or non-pathological) is an important human experience which differs in extent between individuals [20]. Activities of daily living are linked to cognitive function. Cognitive impairment creates significant challenges for patients, their families, and friends, causing cognitive changes in the patients that can interfere with daily activities or independent functioning. The more cognitive functions decline, the more daily functions are inhibited.

Approximately 15 to $20 \%$ of people aging 65 or more have mild cognitive impairment (MCI) [21].

Functional skills deteriorate insidiously over time in patients with early stage dementia or cognitive impairment, examination of functional errors may capture early difficulties that precipitate global functional difficulties [22].

Johansson M (2015), investigated the relationship between cognitive function, ability to perform activities of daily living and perceived health related quality of life in a population of 85 year old individuals in the community of Linkoping ( $\mathrm{n}=373)$. Even mild cognitive dysfunction correlated with impaired ability to perform activities of daily living and lower health related quality of life [16].

James Hall $R$ et al (2011) conducted a study to determine the link between cognitive measures and ADL and IADL functioning among older adults. The result shows, memory and executive functioning were related to IADL scores. Executive functioning was linked to total ADL as well [19].

Boyle P.A et al (2002) had done a research on cognitive and motor impairments predicting functional declines in patients with vascular dementia where it showed that IADL performance is sensitive to early cognitive decline whereas physical functioning is often a significant driver of basic ADL ability.

Early recognition of the cognitive impairment allows the person to reprioritize personal life goals, and to develop advanced directives for health, legal, and financial matters that fit with their preferences [24]. Knowledge of the predictors of functional decline associated with MCI would aid the health care providers in making determinations regarding these individuals' functional independence and disease course. Such predictions would be extremely useful 
for those patients without direct care providers [22].

Henceforth it is important to determine the cognitive abilities and its associated impairments as well as its contributions in the performance of activities of daily living among old-age people. Predicting the effect of cognitive functions in changes of daily functions is essential not only for clinical practitioners to provide appropriate interventions to improve or maintain daily performances but also for care-givers to prepare sufficient socioeconomic resources to treat patients with MCI and dementia. Therefore, the impact of different levels of cognitive functions on the changes in daily living activities in older adults with cognitive impairment must be explored [25]. Taking steps to address this issue will ultimately have a positive impact on the entire community.

From these observations, curiosity and interest in the field the researcher was prompted to undertake the present study. Keeping the view in mind, the researcher has intended to do a study on relationship between cognitive impairment and activities of daily living (ADL) among the elderly people.

\section{MATERIALS AND METHODS Research approach}

To accomplish the objectives of this study, a non experimental approach had been adopted. The survey research approach was considered to be the most appropriate for the present study.

\section{Research design}

The research design depicts the overall plan for organizing a scientific and systematic investigation. Keeping the objectives of the study in view, correlational research design was used.

\section{Research variables}

- Cognitive impairment

- Activities of daily living (ADL)

\section{Demographic variables}

Age, gender, educational qualification, marital status, previous occupation, self financial support, type of family, history of chronic disease (physical), family history of memory loss, history of substance abuse.

\section{Setting of the study}

For Pilot Study, the setting that had been chosen was -

- Ganguly Banprastha Ashram, Duttapukur, North 24 pgs

For Final Study, following settings were chosen -

- Amar Ghar Briddhashram, Madhyamgram, North 24pgs

- Seba Old-age Home, P-9 Panchasayar, Kolkata

- Kasba Divine Foundation, Ballygunj, Kolkata

- Swapna Neerh Old-age Home, Dum Dum Cantonment, Kolkata

- Navanir Old-age Home, Chetla, Kolkata

- Anandaniketan age care home, Barrackpore, North 24pgs

- Bholananda Old-age Home, Barrackpore, North 24pgs

- OLD AGE HOME "Sandhya Mita", Baguiati, Kolkata

- Shanti Elderly Care, Santoshpur, Kolkata

\section{Population of the study}

The population of the present study was elderly people aged 65 years or more living in old-age homes.

\section{Sample}

In the preset study, the sample comprised of the elderly people aging from 65 years or more in selected old-age homes of West Bengal.

\section{Sample size}

Appropriate sample size for the present study was determined by using power analysis formula. Hence, using the standard formula of power analysis, the sample size can be computed as -

Sample size $(\mathrm{n})=\mathrm{Z}^{2} \mathrm{pq} / \mathrm{e}^{2}$ 
Where ' $n$ ' is the sample size that to be calculated; ' $Z$ ' is the standard deviation, the value of which is 1.96 at $95 \%$ confidence level; ' $p$ ' denotes the prevalence rate. For the present study, prevalence rate of cognitive impairment (CI) had been taken as $8.8 \%[58]$; ' $\mathrm{q}$ ' is equal to $(1-\mathrm{p})$ and ' $\mathrm{e}$ ' symbolizes the margin of error, the standard value of which is taken to be $5 \%$ for the present study.

$$
\begin{aligned}
\mathrm{n} & =\mathrm{Z}^{2} \times \mathrm{p} \times \mathrm{q} / \mathrm{e}^{2} \\
& =(1.96)^{2} \times(8.8 / 100) \times(1-8.8 / 100) \\
/(5 / 100)^{2} & \\
& =3.8416 \times 0.088 \times 0.912 / 0.0025 \\
& =0.3083 / 0.0025 \\
& =123.32 \simeq 123 \\
& \text { The sample size by power analysis }
\end{aligned}
$$
was calculated to be 123 . And 150 elderly people were selected for the present study from specific old-age homes of West Bengal.

\section{Inclusion criteria}

Elderly people with the following conditions were included in the study -

- Who were willing to participate in the study.

- Who were present at the period of data collection.

- Who were able to speak and understand English and Bengali.

\section{Exclusion criteria}

- Elderly people who were mentally unable.

\section{Sampling technique}

Simple random sampling technique had been used for the present study.

\section{Ethical consideration}

Ethical permission was taken from -

- IPGME\&R Research Oversight Committee, Institution of Post Graduate Medical Education and Research (IPGME\&R), SSKM hospital, Kolkata20.

- Written informed consent was obtained from the subjects under study.

- Written permission was obtained from the concerned authority of selected oldage homes of West Bengal.
Administrative permission was obtained from -

- Principal of West Bengal Govt. College of Nursing, SSKM Hospital Campus.

- Director of Health Services, Health and Family Welfare Department, West Bengal.

- Joint Director of Health Services Nursing, Health and Family Welfare Department, West Bengal.

- Administrative heads of selected old-age homes of West Bengal.

\section{Data collection tool and technique}

Table 1 Data collection tools and techniques

\begin{tabular}{|l|l|l|}
\hline Tools & $\begin{array}{l}\text { Variables to be } \\
\text { measured }\end{array}$ & Techniques/methods \\
\hline $\begin{array}{l}\text { Semi structured } \\
\text { Interview Schedule }\end{array}$ & Demographic data & Interviewing \\
\hline $\begin{array}{l}\text { GPCOG Screening } \\
\text { Test }\end{array}$ & $\begin{array}{l}\text { Level of cognitive } \\
\text { impairment }\end{array}$ & Interviewing \\
\hline Barthel Index & $\begin{array}{l}\text { Performance of } \\
\text { ADL }\end{array}$ & Observation \\
\hline
\end{tabular}

\section{RESULT}

In the present study, analysis and interpretation of the findings were based on data collected through Semi Structured Interview Schedule on Demographic Data, GPCOG Screening Test to determine the level of cognitive impairment and Barthel Index to assess the performance of activities of daily living (ADL) among elderly people residing in selected old age homes of West Bengal. The analysis was done according to the objectives of the study. Both descriptive and inferential statistics were applied to analyze the data. Results of the analysis of the obtained data were organized by statistical method, so that summarized results could be visualized in scientific way.

\section{Organization and presentation of study findings}

The data obtained were analyzed by using descriptive and inferential statistics. The data were organized and presented under the following sections.

Section I: Findings related to the demographic characteristics of the elderly people of old-age homes. 
Madhurima Kumar et.al. Correlation between the cognitive impairment and the performance of activities of daily living among elderly people residing in selected old-age homes of West Bengal.

Section II: Findings related to identification of cognitive impairment of elderly people.

Section III: Findings related to the level of activities of daily living (ADL) of elderly people.

Section IV: Findings on relationship between the cognitive impairment and the level of activities of daily living (ADL) among the elderly people.

Section V: Findings related to association between the cognitive impairment and selected demographic variables in terms of age, gender, educational qualification, previous occupation, self financial support, type of family, presence of any chronic disease, family history of memory loss.
Section I: Findings related to the demographic characteristics of the sample

Table 2 Frequency and percentage distribution of elderly people according to age, gender, $n=150$

\begin{tabular}{|l|l|l|}
\hline Sample characteristics & Frequency (f) & Percentage (\%) \\
\hline Age (in years) & & \\
$65-74$ & 57 & 38 \\
$75-84$ & 55 & 36.66 \\
$\geq 85$ & 38 & 25.33 \\
\hline Gender & & \\
Male & 76 & 50.66 \\
Female & 74 & 49.33 \\
\hline
\end{tabular}

Table 3 Frequency and percentage distribution of elderly people according to educational qualification, $n=150$

\begin{tabular}{|l|l|l|}
\hline Sample characteristics & Frequency (f) & Percentage (\%) \\
\hline Education & & \\
No formal education & 10 & 6.66 \\
Primary level & 28 & 18.66 \\
Secondary level & 24 & 16 \\
Higher secondary level & 25 & 16.66 \\
Graduation & 45 & 30 \\
Post graduation & 18 & 12 \\
\hline
\end{tabular}

Table 4 Frequency and percentage distribution of elderly people according to marital status and previous occupation $\mathbf{n}=150$

\begin{tabular}{|l|ccc|cc|}
\hline Sample & \multicolumn{3}{|c|}{ Male } & \multicolumn{3}{c|}{ Female } \\
characteristics & Frequency (f) & Percentage (\%) & Frequency (f) & Percentage (\%) \\
\hline Marital status & & & & \\
Married & 06 & 7.89 & 05 & 6.75 \\
Unmarried & 11 & 14.47 & 06 & 8.10 \\
Widower & 55 & 72.36 & Nil & - \\
Widow & Nil & - & 61 & 82.43 \\
Divorcee & 03 & 3.94 & 02 & 2.70 \\
Separated & 01 & 1.31 & Nil & - \\
\hline Previous occupation & & & & Nil & - \\
Farmer & Nil & - & Nil & - \\
Daily wage labour & Nil & - & Nil & - \\
Business & 31 & 40.78 & 13 & 17.56 \\
Service & 45 & 59.21 & 56 & 75.67 \\
Homemaker & Nil & - & 05 & 6.75 \\
Unemployed & Nil & - & \multicolumn{3}{c}{} \\
\hline
\end{tabular}

Table 5 Frequency and percentage distribution of elderly people according to the self financial support, type of family, family history of memory loss, history of substance abuse, $n=150$

\begin{tabular}{|l|l|l|}
\hline Sample characteristics & Frequency (f) & Percentage (\%) \\
\hline Presence of self financial support & & \\
Yes & 91 & 60.66 \\
No & 59 & 39.33 \\
\hline Type of family & & \\
Nuclear & 57 & 38 \\
Joint & 93 & 62 \\
\hline Family history of memory loss & & \\
Yes & 37 & 24.66 \\
No & 113 & 75.33 \\
\hline History of substance abuse & & \\
Yes & 63 & 42 \\
No & 87 & 58 \\
\hline
\end{tabular}

Table 6 Frequency and percentage distribution of elderly people according to the presence of any chronic disease, $n=150$

\begin{tabular}{|l|lc|lc|}
\hline $\begin{array}{l}\text { Sample } \\
\text { characteristics }\end{array}$ & $\begin{array}{l}\text { Male } \\
\text { Frequency (f) }\end{array}$ & Percentage (\%) & $\begin{array}{l}\text { Female } \\
\text { Frequency (f) }\end{array}$ & Percentage (\%) \\
\hline $\begin{array}{l}\text { Presence of chronic disease } \\
\text { Yes }\end{array}$ & 63 & & \\
No & 13 & 82.89 & 65 & 87.83 \\
\hline
\end{tabular}

Section II: Findings related to identification of cognitive impairment of elderly people

Table 7 Frequency and percentage distribution of elderly people according to the presence of cognitive impairment, $n=$ 150

150
\begin{tabular}{|l|l|l|} 
Cognitive impairment & Frequency (f) & Percentage (\%) \\
\hline Present & 65 & 43.33 \\
Not present & 85 & 56.66 \\
\hline
\end{tabular}


Madhurima Kumar et.al. Correlation between the cognitive impairment and the performance of activities of daily living among elderly people residing in selected old-age homes of West Bengal.

Table 8 Range of score, Mean, Median, and Standard Deviation (SD) of elderly people according to the presence of cognitive impairment, $n=150$

\begin{tabular}{|l|l|l|l|l|}
\hline Variable & $\begin{array}{l}\text { Range of } \\
\text { score }\end{array}$ & Mean & Median & SD \\
\hline $\begin{array}{l}\text { Cognitive } \\
\text { impairment }\end{array}$ & $2-9$ & 5.80 & 6 & 2.09 \\
\hline
\end{tabular}

Table 8 depicts that, range of the score of cognitive function of the elderly people was $2-9$ (minimum score -2 and maximum score - 9), mean was 5.80, median was 6 , and the values of both mean and median were nearly same, SD was 2.09 that indicates scores of cognitive function were mildly dispersed.

Section III: Findings related to the level of activities of daily living (ADL) of elderly people

Table 9 Frequency and percentage distribution of elderly people according to the level of activities of daily living (ADL), $\mathbf{n}=150$

\begin{tabular}{|l|l|l|l|}
\hline Level of independence & Range of score & Frequency (f) & Percentage (\%) \\
\hline Independence & 100 & 50 & 33.33 \\
\hline Slight dependency & $91-99$ & 22 & 14.66 \\
\hline Moderate dependency & $61-90$ & 65 & 43.33 \\
\hline Severe dependency & $21-60$ & 13 & 8.66 \\
\hline Totally dependency & $0-20$ & Nil & - \\
\hline
\end{tabular}

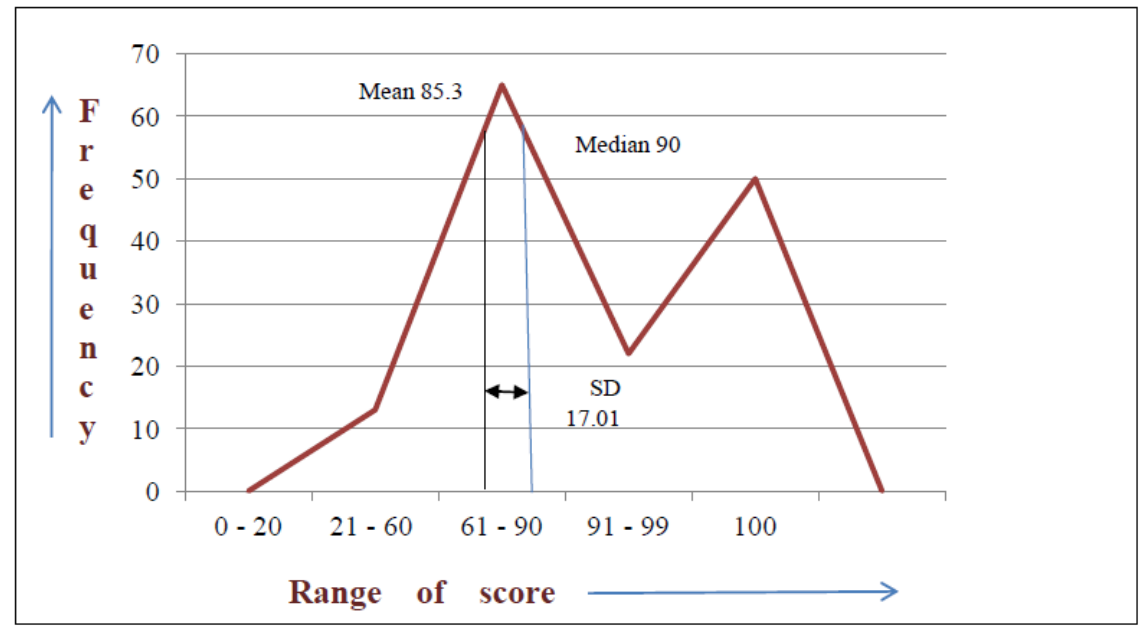

Fig 1 Frequency polygon showing distribution of activities of daily living scores of elderly people, $n=150$

The figure shows that majority of the participants (65) lie in the score range of 61 - 90. The figure also denotes mean as 85.3, median as 90 and standard deviation as 17.01. Here the mean lies to the left of the median indicating negative skewness (Sk) which was -0.82 .

Section IV: Findings on relationship between the cognitive impairment and the activities of daily living (ADL) among the elderly people

Table 10 Correlation between the cognitive impairment and the activities of daily living (ADL) among the elderly people, $n$ $=150$

\begin{tabular}{|l|l|l|}
\hline \multicolumn{1}{|c|}{ Variable } & 'r' & ' $\mathbf{~}$ ' \\
\hline $\begin{array}{l}\text { Cognitive impairment and Activities of daily } \\
\text { living (ADL) }\end{array}$ & 0.87 & $21.48^{* * *}$ \\
\hline \multicolumn{3}{|c|}{$' t$ ' $d f(148)=3.35, p<0.001$} \\
\hline
\end{tabular}

Table 10 reveals that there was a strong positive correlation $(0.87)$ between cognitive impairment and activities of daily living (ADL) which was also found significant from ' $\mathrm{t}$ ' value of 21.48 at 0.001 level of significance. Therefore it can be interpreted that, those who were cognitively impaired also had a lower level of ADL.

Section V: Findings related to association between the cognitive impairment and selected demographic variables in terms of age, gender, educational qualification, previous occupation, self financial support, type of family, presence of any chronic disease, family history of memory loss

Table 11 Correlation between the cognitive impairment and age of the elderly people, $n=150$

\begin{tabular}{|l|l|l|}
\hline Variable & 'r' & 't' \\
\hline $\begin{array}{l}\text { Cognitive impairment and Age of the elderly } \\
\text { people }\end{array}$ & 0.97 & $54.52^{* * *}$ \\
\hline \multicolumn{3}{|l|}{$' t$ ' $d f(148)=3.35, p<0.001$}
\end{tabular}


Madhurima Kumar et.al. Correlation between the cognitive impairment and the performance of activities of daily living among elderly people residing in selected old-age homes of West Bengal.

Table 11 reveals that there was a strong positive correlation $(0.97)$ between the presence of cognitive impairment and age of the participants, which was also found significant from ' $t$ ' value of 54.52 at 0.001 level of significance. Therefore it can be interpreted that, cognitive impairment is evident with advancement of age.

Table 12 Chi square value showing association between the cognitive impairment and selected demographic variables (gender and educational qualification) $\mathbf{n}=\mathbf{1 5 0}$

\begin{tabular}{|c|c|c|c|c|}
\hline Selected variables & $\begin{array}{lr}\text { Cognitive impairment } \\
\text { Yes }\end{array}$ & Total & Chi square & p value \\
\hline $\begin{array}{l}\text { Gender } \\
\text { Male } \\
\text { Female } \\
\text { Total } \\
\end{array}$ & $\begin{array}{l}26 \\
40 \\
66 \\
\end{array}$ & $\begin{array}{l}76 \\
74 \\
150 \\
\end{array}$ & $5.99 *$ & 0.014 \\
\hline $\begin{array}{l}\text { Educational qualification } \\
\text { No formal education } \\
\leq \text { Secondary level } \\
>\text { Secondary level } \\
\text { Total }\end{array}$ & $\begin{array}{c}01 \\
27 \\
56 \\
84\end{array}$ & $\begin{array}{l}10 \\
52 \\
88 \\
150\end{array}$ & $8.81^{*}$ & 0.012 \\
\hline
\end{tabular}

Data further displayed in table 12 shows that among the male respondents, 26 were having cognitive impairment and 50 were cognitively intact. As well as among all the female respondents, 40 had cognitive impairment and 34 were cognitively sound.

Chi square value was calculated to determine the association between presence of cognitive impairment and gender of the respondents, which was found 5.97 for $\mathrm{df}$ (1) at 0.05 level of significance. It could be thus concluded that the presence of cognitive impairment was significantly associated with the gender of the respondents.

Data displayed in table 14 reveals that among the respondents who had no formal education 9 participants had cognitive impairment and only 1 participant was cognitively sound. Similarly, among the participants who had $\leq$ secondary level of education, 25 were having cognitive impairment and 27 were cognitively intact. For those whose educational qualifications were more than secondary level, among them 32 respondents had cognitive impairment and the remaining 56 respondents did not have any cognitive impairment.

Chi square value was computed to determine the association between presence of cognitive impairment and educational qualification of the respondents, which was found 8.79 for $\mathrm{df}$ (2) at 0.05 level of significance. Thus it could be concluded that presence of cognitive impairment was dependent on the educational qualification of the respondents.

Table 13 Chi square value showing association between the cognitive impairment and selected demographic variables (previous occupation and self financial support), $\mathbf{n}=\mathbf{1 5 0}$

\begin{tabular}{|c|c|c|c|c|}
\hline Selected variables & $\begin{array}{l}\text { Cognitive impairment } \\
\text { Yes }\end{array}$ & Total & Chi square & p value \\
\hline $\begin{array}{l}\text { Previous occupation } \\
\text { Business } \\
\text { Service } \\
\text { Home maker } \\
\text { Unemployed } \\
\text { Total }\end{array}$ & $\begin{array}{c}17 \\
43 \\
22 \\
03 \\
85\end{array}$ & $\begin{array}{l}31 \\
58 \\
56 \\
05 \\
150\end{array}$ & $12.80 * *$ & 0.005 \\
\hline $\begin{array}{l}\text { Self financial support } \\
\text { Yes } \\
\text { No } \\
\text { Total }\end{array}$ & $\begin{array}{c}61 \\
24 \\
85\end{array}$ & $\begin{array}{l}91 \\
59 \\
150\end{array}$ & $10.12 * *$ & 0.001 \\
\hline
\end{tabular}

Data represented in table 13 shows that the 5 respondents who were unemployed, among them, only 2 respondents had cognitive impairment and the rest were cognitively sound. Similarly among the respondents who were home- 
makers, 34 respondents had cognitive impairment and 22 respondents did not cognitive impairment. As well as among the 58 participants who were service holders, 15 had cognitive impairment and the rest 43 were cognitively intact. And among those with business as the previous occupation, 14 had cognitive impairment and remaining 17 were cognitively sound.

Chi square value was computed to determine the association between presence of cognitive impairment and the previous occupation of the respondents, which was found to be 12.852 for df (3) at 0.01 level of significance. Hence it could be concluded that presence of cognitive impairment was significantly associated with the previous occupation of the respondents.
Table 15 further depicted that among the respondents who had self financial support, 30 were having cognitive impairment and 61 were cognitively sound. And the remaining participants who did not have any kind of self finances, among them, 35 had cognitive impairment and the rest 24 participants were cognitively intact.

Chi square value was calculated to determine the association between presence of cognitive impairment and the presence of self financial support of the respondents, which was found 10.1 for df (1) at 0.01 level of significance. Hence it could be depicted that presence of cognitive impairment was dependent on the presence of self financial support of the respondents.

Table 14 Chi square value showing association between the cognitive impairment and selected demographic variables (type of family, presence of any chronic disease and family history of memory loss), $n=150$

\begin{tabular}{|c|c|c|c|c|}
\hline Selected variables & $\begin{array}{l}\text { Cognitive impairment } \\
\text { Yes }\end{array}$ & Total & Chi square & p value \\
\hline $\begin{array}{l}\text { Type of family } \\
\text { Nuclear } \\
\text { Joint } \\
\text { Total }\end{array}$ & $\begin{array}{r}44 \\
41 \\
85 \\
\end{array}$ & $\begin{array}{l}57 \\
93 \\
150 \\
\end{array}$ & $15.75 * * *$ & 0.00007 \\
\hline $\begin{array}{l}\text { Presence of chronic } \\
\text { disease (physical) } \\
\text { Yes } \\
\text { No } \\
\text { Total } \\
\end{array}$ & $\begin{array}{l}56 \\
04 \\
60 \\
\end{array}$ & $\begin{array}{l}128 \\
22 \\
150 \\
\end{array}$ & $5.1^{*}$ & 0.042 \\
\hline $\begin{array}{l}\text { Family history of } \\
\text { memory loss } \\
\text { Yes } \\
\text { No } \\
\text { Total }\end{array}$ & $\begin{array}{l}15 \\
43 \\
58\end{array}$ & $\begin{array}{l}37 \\
113 \\
150\end{array}$ & 0.07 & 0.787 \\
\hline
\end{tabular}

Data displayed in table 16 shows that respondents who belonged to nuclear family, among them, 13 respondents had cognitive impairment and 44 respondents were cognitively intact. Similarly, respondents who belonged to joint family, among them, 52 respondents had cognitive impairment and 41 respondents were cognitively intact.

Chi square value was calculated to determine the association between presence of cognitive impairment and the family type of the respondents, which was found to be 15.75 for df (1) at 0.001 level of significance which was more than the table value. Thus it could be interpreted that presence of cognitive impairment was dependent on the family type of the respondents.

Data displayed in table 16 reveals that respondents who had chronic disease (physical), among them, 56 respondents had cognitive impairment and 72 respondents were cognitively intact. Similarly respondents who had no history of any chronic illness, among them, 4 respondents had cognitive impairment and 18 did not have cognitive impairment.

Chi square value was computed to determine the association between presence of cognitive impairment and the presence of any chronic disease of the respondents, which was found 5.1 for $\mathrm{df}$ (1) at 0.05 level of significance. Hence it could be concluded 
that presence of cognitive impairment was dependent on the presence of any chronic disease of the respondents.

Data displayed in table 16 depicts that respondents who had family history of memory loss, among them, 15 had cognitive impairment and 22 were cognitively sound. Similarly, among the respondents who had no family history of memory loss, 43 respondents had cognitive impairment and 70 respondents did not have cognitive impairment.

Chi square value was calculated to determine the association between presence of cognitive impairment and family history of memory loss of the respondents, which was found to be 0.07 for $\mathrm{df}(1)$ at 0.05 level of significance. Hence it could be interpreted that presence of cognitive impairment was independent on the family history of memory loss of the respondents.

\section{DISCUSSION}

Discussion of the major findings in relation to other studies are presented below -

Discussion of the major findings in relation to other studies are presented below -

\section{Findings related to demographic} characteristics of the elderly people

The findings of the present study revealed that majority $(38 \%)$ of elderly people belonged to the age group of 65 to 74 years.

Gamage MWK, Hewage C, Pathirana KD (2019) conducted a descriptive cross sectional study on the associated factors for cognition of physically independent elderly people. The findings revealed that $42.8 \%$ of participants belonged to the age $\leq 70$ years, with a mean age of $71.9 \pm 6.7$ years which were consistent with the present study findings [26].

The findings of the present study also revealed that $50.66 \%$ of the elderly people were male and majority of the elderly people that is, $58 \%$ had never abused substances.
These findings were consistent with the findings of the descriptive study on cognitive functioning and associated factors in older adults by Peltzer K et al (2019) which showed that $55.3 \%$ of elderly people were male followed by, $65.4 \%$ with no history of substance abuse [32].

Abbasian M, Ghalichi F, Ahmadi

B et al. (2016) conducted a cross-sectional study on the status of daily living activities among older people. The study resulted in majority of the participants to be male $(59.3 \%)$ which was consistent with the present study [31].

The findings of the present study showed that majority of the participants (30\%) were graduates, followed by primary and higher secondary level education. It also revealed that majority of the respondents were widowed $(72.36 \%$ widower, $82.43 \%$ widow).

The findings of the present study were consistent with the findings of the cross sectional study on cognitive impairment and associated factors among institutionalized elderly person by Roig JJ et al (2017) which showed that $71 \%$ of participants had higher level of education. Marital status showed that $79 \%$ of the elderly people were widowed [33].

Poddar K, Kant S, Singh A, Singh TB (2011) conducted a cross-sectional epidemiological study of dementia among the habitants of Eastern Uttar Pradesh, India. The study findings which were similar to that of the present study revealed that, Widows/widowers/unmarried had a double prevalence $(9.3 \%)$ as compared with married (4.3\%) people [29].

The findings of the present study revealed that majority of the elderly people that is $62 \%$, belonged to joint families.

Santos AA dos (2012) conducted descriptive study on family functionality regarding the elderly with cognitive impairments. The findings were in consistence with the present study findings that was $76.4 \%$ of participants belonged from the extended families [34]. 
The present study findings showed that among 150 participants, majority $(38.6 \%)$ were service holders, followed by $37.3 \%$ of participants who were home makers.

The findings were consistent with the findings of the longitudinal study on the impact of occupational experience on cognitive and physical functional status among older adults by Min JY, Park JB et al (2015) which showed that majority of the respondents' $(63.1 \%$ - male, $66.5 \%$ female) principal job type during lifetime was manual work i.e., service [35].

Another descriptive study on an investigation into the prevalence of cognitive impairment and the performance of older adults by Soleimani $\mathbf{R}$, Shokrgozar $S$ et al (2018) revealed that majority of the elderly people (41.7\%) were housewives [36].

The findings of the present study revealed that majority of the participants, that is, $75.33 \%$ had no family history of memory loss.

The findings were similar with the findings of the descriptive study on age, family history and memory and future risk for cognitive impairment by Locke DEC, Ivnik RJ et al (2009) which showed that $35 \%$ of the sample reported a family history of dementia and remaining did not have any family history of memory loss [37].

The findings of the present study revealed that majority of the respondents, that is, $(89.18 \%$ - female, $81.57 \%$ - male) had chronic diseases.

Kim J, Park E et al (2019), conducted descriptive study on the cognitive impact of chronic diseases on functional capacity in older adults. The findings were consistent with the present study findings. As per the study, the majority of the participants reported to have chronic illnesses, i.e., either hypertension $(40.0 \%)$ or DM (10\%) or other conditions (15.6\%) [38].

The findings of the present study revealed that majority of the elderly people $(60.66 \%)$ had some self financial support.
The current study findings were consistent with the findings of the descriptive study on the impact of transfer on cognitive impairment in the elderly by Weng $W$ et al (2018) which showed that majority $(59.9 \%)$ of the participants had some sort financial back up that is, various allowance, property and pension [39].

Findings related to identification of cognitive impairment of elderly people

The findings of the present study revealed that cognitive impairment was evident among $43.33 \%$ of the elderly people and remaining $56.66 \%$ of the respondents had no cognitive impairment.

Similarly the findings were in consistence with the findings of the descriptive study on an investigation into the prevalence of cognitive impairment and the performance of older adults by Soleimani R, Shokrgozar S et al (2018) which founded that $37 \%$ of the older adults had mild cognitive impairment [36].

The findings have also in similarities with the findings of the descriptive study on the prevalence of cognitive impairment by Unverzagt FW, Gao $S$ et al (2001), revealing that the overall rating of cognitive impairment among community dwelling elderly was $23.4 \%$ [40].

The findings were consistent with the findings of the descriptive study on the prevalence of cognitive impairment and its associated socio demographic variables using mini mental status examination among elderly population by Patel RM, Singh US (2018) which showed that the overall prevalence of CI was $25 \%$ [27].

Findings related to the level of activities of daily living (ADL) of elderly people

The findings of the present study showed that majority of the respondents that is, $43.33 \%$ were moderately dependent, $33.33 \%$ were independent, $14.66 \%$ were slightly dependent followed by $8.66 \%$ of the participants who were severely dependent.

The findings were consistent with the findings of the descriptive study on the 
determinants of $\mathrm{ADL}$ and IADL in older adults by Sozanski B et al (2019) which founded that $37.5 \%$ of the participants reported at least one problem with IADLs. At least one problem with ADLs was reported by $17.13 \%$ of the participants [30].

Sjolund BM, Wimo A, Strauss EV et al (2015), conducted a longitudinal study on incidence of ADL disability in older persons, physical activities as a protective factor. The findings were in consistence with the findings that the incidence rates for male were similar in the age groups 78-81 and 84 years and older 42.3 vs. $42.5 / 1000$ persons-years. For women the incidence rate had a significant rise for ADL disability from the age group 78-81 years to the age group 84 years and older, 20.8 vs. 118.3/1000 persons-years [41].

Findings on relationship between the cognitive impairment and the activities of daily living (ADL) among the elderly people

The findings of the present study revealed a strong positive correlation between the two variables; Cognitive impairment and activities of daily living (ADL).

The findings were consistent with the findings of the descriptive study on the correlation between cognitive functions and activities of daily living by Biben $\mathbf{V}$, Ong PA (2016), which showed that there is a significant correlation between cognitive functions and IADL among post stroke patients. The only cognitive domain positively correlated with IADL was orientation to time and verbal recall $(\mathrm{r}=$ $0.517, \mathrm{p}=0.03$ ) [42].

The present study findings were similar with the findings of the descriptive study on the relationship between functional fitness and cognitive impairment in older adults by Yang $M$ et al (2017) which founded that the rate of ADL disability was significantly higher in the CI group. The older adults with cognitive impairment (CI) had significantly lower frequency of 30 s chair stand, 30s arm curl and 2 min step, and relatively longer time to complete the 8 foot up-and-go, shorter chair sit-and-reach an back scratch distance than the non-CI group [43].

Findings related to association between the cognitive impairment and selected demographic variables

The findings of the present study also revealed that, there is a strong positive correlation between the presence of cognitive impairment and age of the participants.

Sharma D, Mazta SR, Parashar A (2013) conducted a cross-sectional population based descriptive study on the prevalence of cognitive impairment and related factors among elderly. The result revealed that, in the logistic regression model, increased age (odds ratio $=2.2-22.2$; significant at $\mathrm{P}<0.05$ ) showed a higher probability of cognitive impairment [28].

The findings of the present study revealed that there is significant association among age, gender, educational qualification of the participants and cognitive impairment of the participants.

Poddar K, Kant S, Singh A, Singh TB (2011) conducted a cross-sectional epidemiological study of dementia among the habitants of Eastern Uttar Pradesh, India. The study findings got similarities with the present study that revealed, the age $\left(\chi^{2}=49.9, \mathrm{df}=5\right)$, gender $\left(\chi^{2}=16.60, \mathrm{df}=\right.$ $1)$, education $\left(\chi^{2}=111.0, \mathrm{df}=3\right)$ were found to be significantly associated with dementia [29].

The current study findings have similarities with the findings of the descriptive study on an investigation into the prevalence of cognitive impairment and the performance of older adults by Soleimani R, Shokrgozar S et al (2018). They founded that gender of the respondents, age of the respondents and educational qualification of the participants were associated with the level of cognitive impairment of the participants [36].

The findings of the present study determined that there is a significant association between presence of any chronic 
illness and cognitive impairment of the participants.

Unverzagt FW, Gao S et al (2001), conducted a descriptive study on the prevalence of cognitive impairment. The findings which were consistent with the present study showed that cognitive impairment was dependent on the presence of any chronic disease of the respondents [40].

The findings of the present study determined that there is significant association between previous occupation and self financial support of the participants and cognitive impairment of the participants.

The findings were in consistence with the findings of the descriptive study on the prevalence of cognitive impairment and its associated socio demographic variables using mini mental status examination among elderly population by Patel RM, Singh US (2018). They founded that occupation/profession and economic class of the respondents are significantly associated with cognitive impairment of the participants [27].

Poddar K, Kant S, Singh A, Singh TB (2011) conducted a cross-sectional epidemiological study of dementia among the habitants of Eastern Uttar Pradesh, India. The study findings got similarities with the present study that revealed that, occupation $\left(\chi^{2}=17.13, \mathrm{df}=3\right)$ was significantly associated with dementia [29].

\section{CONCLUSION}

From the present study, it was funded that majority of elderly people with cognitive impairment belonged to the age group 65 to 84 years. Among 150 participants, $43.33 \%$ had cognitive impairment and majority of the elderly people were moderately dependent according to the ADL scale. It was revealed that significant relationship exists between cognitive impairment and activities of daily living (ADL). Present study also depicted that age, gender, educational qualification, previous occupation, self financial support, family type, presence of any chronic illness (physical) of the respondents were significantly associated with cognitive impairment of the participants.

\section{Acknowledgement: None}

\section{Conflict of Interest: None}

\section{Source of Funding: None}

\section{Ethical Approval: Approved}

\section{REFERENCES}

1. Townsend MC. Psychiatric Mental Health Nursing, Concepts of Care in Evidence Based Practice. $5^{\text {th }}$ ed. New Delhi: Jaypee Publishers; 2014. p 748-50

2. Life Expectancy: Latest Current Affairs and News. Current Affairs Today - Page 1 [Internet]. Currentaffairs.gktoday.in. 2020 [cited 21 April 2020]. Available from:

https://currentaffairs.gktoaday.in/tags/lifeexpectancy/page/1

3. Fagundes SD, Silva MT, Thees MF, Pereira MG. Prevalence of dementia among elderly Brazilians: a systematic review. Sao Paulo Medical Journal. 2011 Jan; 129(1): $46-50$

4. Sadeghi M, Kazemi HR. Prevalence of Dementia and Depression among Residents of Elderly Nursing Homes in Tehran Province. IJPCP. 2004; 9(4): 49 55

5. Yang M, Guo J, Gong J, Deng M, Yang $\mathrm{N}$, Yan Y. Relationships between functional fitness and cognitive impairment in Chinese communitydwelling older adults: a cross-sectional study. BMJ Open. 2018; 8(5): e020695. doi:10.1136/bmjopen-2017-020695

6. Murman DL. The impact of age on cognition. Semin Hear. 2015; 36(3): 111 121. doi: $10.1055 / \mathrm{s}-0035-1555115$

7. Cognitive skill [Internet]. En.wikipedia.org.2020 [cited 21 April 2020]. Available from: https://en.wikipedia.org/wiki/Cognitive_s kill

8. Ferreira PCS, Tavares DMS, Rodrigues RAP. Socio demographic characteristics, 
Madhurima Kumar et.al. Correlation between the cognitive impairment and the performance of activities of daily living among elderly people residing in selected old-age homes of West Bengal.

functional status and morbidity among older adults with and without cognitive decline. Acta Paul Enferm. 2011; 24(1): $29-35$

9. Sobral AIGP, Araujo CMT, Sobral MFF. Mild cognitive impairment in the elderly Relationship between communication and functional capacity. Dement Neuropsychol. 2018 Apr-Jun; 12(2): 165 172. doi: $10.1590 / 1980-57642018 \mathrm{dn} 12-$ 020009

10. Wiener JM, Hanley RJ. Measuring the activities of daily living among the elderly: A guide to National Surveys. [Internet]. 1989; Available from: https://aspe.hhs.gov/basic-

report/measuring-activities-daily-livingamong-elderly-guide-national-surveys

11. An JH, Lee KE, Jeon HJ, Son S, Kim S, Hong J. Risk of suicide and accidental deaths among elderly patients with cognitive impairment. Alzheimer's Research and Therapy. 2019 April; 11(1). Available from: https://link.springer.com/article/10.1186/s 13195-019-0488-X

12. Fu C, Li Z, Mao Z. Association between Social Activities and Cognitive Function among the Elderly in China: A CrossSectional Study. Int J Environ Res Public Health. 2018; 15(2): 231. [cited 2018 January 30]. doi: 10.3390/ijerph15020231

13. Janoutova J, Sery O, Hosak L, Janout V. Is mild Cognitive Impairment a Precursor of Alzheimer's Disease? Short Review. Cent Eur J Public Health. 2015; 23(4): 365 - 367. doi: 10.21101/cejph.a4414

14. Lara E, Koyanagi A, Caballero F, Miret M, Domenche-Abella J, Olaya B et al. Cognitive reserve is associated with quality of life: A population-based study. Experimental Gerontology. 2017; 87: 67 73

15. Mograbi DC, Faria Cde A, Fichman HC, Paradela EM, Lourenco RA. Relationship between activities of daily living and cognitive ability in a sample of older adults with heterogeneous educational level. Ann Indian Acad Neurol. 214; 17(1): 71 - 76 . doi: $10.4103 / 0972-$ 2327.128558
16. Johansson MM, Marcusson J, Wressle E. Cognitive impairment and its consequences in everyday life: experiences from people with mild cognitive impairment or mild dementia and their relatives. International Psychogeriatrics. 2015; 27(6): 949 - 958. doi:10.1017/S1041610215000058

17. Dufoil C, Beiser A, Chene G, Seshadri S. Are trends in dementia incidence associated with compression in morbidity? Evidence from The Framingham Heart Study. The Journals of Gerontology. 2018 April; 73(1): S65-S72. Available from: https://doi.org/10.1093/geronb/gby001

18. Heyn PC, Abreu BC, Ottenbacher KJ. The effect of Exercise Training on Elderly Persons with Cognitive Impairment and dementia: A Meta-Analysis. Archives of physical medicine and rehabilitation. 2004 Nov; 85(10): 1694 - 1704.doi: 10.1016/j.apmr.2004.03.019

19. Hall J, Vo H, Johnson L, Barber R, O'Bryant S. The link between cognitive measures and ADLs and IADL functioning in mild Alzheimer's: What has gender got to do with it?. International Journal of Alzheimer's Disease. 2011; 2011: $1-6$

20. Deary IJ, Corley J, Gow AJ, Harris SE et al. Age associated cognitive decline. British Medical Bulletin. 2009; 92(1): 135 - 52. doi: 10.1093/bmb/ldp033

21. Alzheimer's Disease and Dementia [Internet]. Alzheimer's Association. 2019. Available from: https://www.alz.org/alzheimerdementia/what-is-dementia/relatedconditions/mild-cognitive-impairment

22. Jefferson AL, Byerly LK, Vanderhill S et al. Characterization of Activities of Daily Living in Individuals with Mild Cognitive Impairment. Am J Geriatr Psychiatry. 2008; 16(5): 375 - 383. doi: 10.1097/JGP.0b013e318162f97

23. Mlinac ME, Feng MC. Assessment of activities of daily living, self-care, and independence. Archives of Clinical Neuropsychology. 2016 Aug; 31(6): 506 516

24. Morley JE, Morris JC, Weger MB, Borson S, Carpenter BD, Campo ND et al. Brain 
Madhurima Kumar et.al. Correlation between the cognitive impairment and the performance of activities of daily living among elderly people residing in selected old-age homes of West Bengal.

Health: The Importance of Recognizing Cognitive Impairment: An IAGG Consensus Conference. J Am Med Dir Assoc. 2015 Sep; 16(9): 731 - 739.doi: 10.1016/j.jamda.2015.06.017

25. Lee MT, Jang Y, Chang WY. How do impairments in cognitive functions affect activities of daily living functions in older adults? Plos One. 2019; 14(6): e0218112. doi: 10.1371/journal.pone.0218112

26. Gamage MWK, Hewage C, Pathirana KD. Associated factors for cognition of physically independent elderly people living in residential are facilities for the aged in Sri Lanka. BMC Psychiatry. 2019; 19(10). Available from: https://doi.org/10.1186/s12888-018-20035

27. Patel RM, Singh US. Prevalence study of cognitive impairment and its associated socio-demographic variables using minimental status examination among elderly population residing in field practice areas of a medical college. Indian Journal of Community Medicine. 2018; 43(2): 113 116

28. Sharma D, Mazta SR, Parashar A. Prevalence of cognitive impairment and related factors among elderly: A population-based study. Journal Dr. NTR University of Health Sciences. 2013; 2(3): $171-176$. doi: $10.4103 / 2277$ 8632.117182

29. Poddar K, Kant S, Singh A, Singh TB. An epidemiological study of dementia among the habitants of Eastern Uttar Pradesh, India. Ann Indian Acad Neurol. 2011; 14(3): 164 - 168. doi:10.4103/09722327.85874

30. Cwirlej-Sozanska A, Sozanski B, Pietruszynska AW, Szurlej AW. Determinants of ADL and IADL disability in older adults in Southern Poland. BMC Geriatr. 2019; 19: 297. Doi:10.1186/s12877-019-1319-4

31. Abbasian M, Ghalichi F, Ahmadi B, Ghasemzadeh P, Esmaeilpour E, Matlabi H. Status of Daily Living Activities among Older People in Maku. Elderly Health Journal. 2016; 2(2): 73 - 77

32. Pelitzer K, Pengpid S, Susilowati IH. Cognitive Functioning and Associated
Factors in Older Adults: Results from the Indonesian family Life Survey - 5 (IFLS5) in 2014-2015. Current Gerontology and Geriatric Research. 2019; 4527647. Available from: https://doi.org/10.1155/2019/4527647

33. Andrade FLJP de, Lima JMR de, Fidelis KNM, Roig JJ, Lima KC de. Cognitive impairment and associated factors among institutionalized elderly persons in Natal, Rio Grand do Norte, Brazil. Revista Brasileira de Geriatria e Gerentologia. 2017; 20(2): 186 - 196. Available from: http://dx.doi.org/10.1590/198122562017020.160151

34. Santos AA dos, Pavarini SCI. Family functionality regarding the elderly with cognitive impairments: the caretaker's perception. Revista da Escola de Enfermagem da USP. 2012 Oct; 46(5): 1140 - 6. Available from: https://doi.org/10.1590/S008062342012000500015

35. Min JY, Park JB, Lee KJ, Min KB. The impact of occupational experience on cognitive and physical functional status among older adults in a representative sample of Korean subjects. Ann Occup Environ Med. 2015 Mar; 27: 11. doi:10.1186/s40557-015-0057-0

36. Soleimani R, Shokrgozar S, Fallahi M, Kafi H, Kiani M. An investigation into the prevalence of cognitive impairment and the performance of older adults in Guilan province. J Med Life. 2018; 11(3): 247 253. doi:10.25122/jml-2018-0017

37. Locke DEC, Ivnik RJ, Cha RH, Knopman DS, Tangalos EG, Boeve BF et al. Age, family history and memory and future risk for cognitive impairment. J Clin Exp Neuropsychol. 2009; 31(1): 111 - 116. doi:10.1080/13803390802020443

38. Kim J, Park E, An M. The Cognitive Impact of Chronic Diseases on Functional Capacity in Community-Dwelling Adults. J Nurs Res. 2019 Feb; 27(1): $1-8$. doi:10.1097/jnr.0000000000000272

39. Weng W, Liang J, Xue J, Zhu T, Jiang Y, Wang $\mathbf{J}$ et al. The Transfer Effects of Cognitive Training on Working Memory Among Chinese Older Adults With Mild Cognitive Impairment: A Randomized 
Madhurima Kumar et.al. Correlation between the cognitive impairment and the performance of activities of daily living among elderly people residing in selected old-age homes of West Bengal.

Controlled Trial. Front Aging Neurosci. 2019;

11:

212.

doi:10.3389/fnagi.2019.00212

40. Unverzagt FW, Gao S et al. Prevalence of cognitive impairment-Data from the Indianapolis Study of Health and Aging. Neurology. 2001; 57(9): 1655 - 1662. doi:10.1212/WNL.57.9.1655

41. Sjolund BM, Wimo A, Strauss EV, Engstrom M. Incidence of ADL disability in older persons, physical activities as a protective factor and the need for informal and formal care-results from the SNAC-N project. PLoS One. 2015; 10(9): e0138901. doi:10.1371/journal.pone.0138901

42. Prakoso K, Biben V, Ong PA. Correlation between Cognitive Functions and Activity of Daily Living among Post-stroke Patients. Althea Medical Journal. 2016; 3: 329 - 333. doi:10.15850/amj.v3n3.874

43. Yang M, Guo Y, Deng M, Yang N, Yan Y. Relationship between functional fitness and cognitive impairment in Chinese community-dwelling older adults: a crosssectional study. BMJ Open. 2018; 8(5): 1 -6. doi:10.1136/bmjopen-2017-020695

How to cite this article: Kumar M, Modak S. Correlation between the cognitive impairment and the performance of activities of daily living among elderly people residing in selected old-age homes of West Bengal. Int $J$ Health Sci Res. 2021; 11(10): 72-87. DOI: https://doi.org/10.52403/ijhsr.20211011 